Motrivivência $\quad$ Ano XXII, No 35, P. 62-78 $\quad$ Dez./2010

doi: 10.5007/2175-8042.2010v22n35p62

\title{
O REORDENAMENTO DO TRABALHO DO PROFESSOR DE EDUCAÇÃO FÍSICA E A ORGANIZAÇÃO EMPRESARIAL DO ÂMBITO DO FITNESS: CONFEF/CREF, ACAD e SINDACAD ${ }^{1}$
}

Tatiane Carneiro Coimbra²

\begin{abstract}
RESUMO
O presente artigo insere-se em um esforço de compreender a organização empresarial do âmbito do fitness a partir dos anos de 1990. Especificamente busca estabelecer as relações entre essas organizações. Para tanto, realiza um percurso histórico referente à criação das três instituições aqui tratadas, buscando aclarar os seus interesses de classe. Ainda procura através das revistas das organizações estabelecer a relação entre elas. Por fim, conclui-se que as três organizações mantêm íntimas relações agindo de acordo com os seus interesses de classe o que precariza intensamente o trabalho do professor de educação física. Os organismos representantes da burguesia do âmbito do fitness aqui tratados são: o sistema CONFEF/CREF, a ACAD (Associação das Academias do Brasil) e o SINDACAD (Sindicato dos proprietários das academias de ginástica).
\end{abstract}

Palavras-chave: Trabalho. Educação Física. Burguesia do âmbito do fitness.

1 A discussão aqui tratada é parte da dissertação de mestrado da autora, defendida na Universidade Federal Fluminense, no Programa de Pós-Graduação em educação, no ano de 2009.

2 Mestre em Educação - UFF. Contato: tc_coimbra@yahoo.com.br 


\section{Introdução}

Historicamente a Educação Física, no Brasil, se ocupou da formação física do corpo trabalhador, sendo disciplina central do projeto de formação humana dominante durante décadas. Suas principais tendências foram: a higienista, a militarista e a esportivista ou tecnicista. Contudo, a partir dos anos de 1980, sob a égide da pedagogia das competências, como nova referência educacional ${ }^{3}$ a Educação Física perde centralidade. (NOZAKI, 2004). A formação escolar tendo como um dos eixos norteadores a pedagogia das competências objetiva a formação do trabalhador polivalente, apto a desenvolver inúmeras funções durante toda a vida produtiva, a resolução de problemas, capacidade de abstração, trabalho em equipe, criatividade, conhecimentos gerais e técnico tecnológicos (língua inglesa e informática, por exemplo), se tornam atributos necessários à fase competitiva do capitalismo. (FRIGOTTO, 1996)

Nesse cenário, a cultura corporal continua a ser apropriada pela classe dominante, hoje, sobretudo, na forma de mercadoria, a ser comercializada, mormente nas academias de ginástica. Até a década de 1980, o professor de Educação Física poderia ser caracterizado predominantemente como um trabalhador assalariado da iniciativa pública ou privada. No entanto, a partir da referida década, as academias de ginástica ganharam grande espaço, no Brasil, impulsionadas pela política de desobrigação do Estado no que concerne à garantia aos direitos sociais, dentre eles a saúde, por conseguinte, observamos a investida da iniciativa privada em gerir tais bens. Desse modo, inicia-se o processo de reordenamento do trabalho do professor de Educação Física. Tais mudanças inserem-se em um contexto de reestruturação produtiva, neoliberalismo e o conseqüente aumento da exploração da força de trabalho, representado, sobretudo, pelo aumento da precarização do trabalho, cujo objetivo é a manutenção da sociedade capitalista.

O reordenamento no trabalho do professor de Educação Física trouxe à cena, uma série de

3 Na década de 1970, o mundo assistiu a mais uma crise cíclica do modo de produção capitalista, que teve como expressões fenomênicas a falência do padrão de acumulação taylorista-fordista e do estado de bem estar social. Na tentativa de ganhar sobrevida, o sistema capitalista passa por modificações tendo como principais referências o padrão de acumulação flexível e o neoliberalismo, que demanda ajustes em vários planos, dentre eles o educacional, que passa a ter como principal referência a pedagogia das competências. Com vistas a formação do trabalhador de novo tipo. 
questões referentes a essa profissão: mudanças no conteúdo do trabalho, aumento na precarização do trabaIho, regulamentação da profissão, transformações no que se refere à formação profissional da área e organização de classe dos empresários do âmbito do fitness.

A partir dos anos de 1990, a burguesia do setor do fitness começa a se organizar enquanto classe. Essa organização culminou na criação dos organismos denominados aqui de organismos representantes da burguesia do âmbito do fitness.

\section{A formação dos organismos representantes da burguesia do setor do fitiness}

A profissão da Educação Física foi regulamentada pela lei 96.96/98, de $1^{\circ}$ de setembro de 1998, sancionada pelo então Presidente da República, Fernando Henrique Cardoso. A referida lei criou também o sistema CONFEF/CREF. De acordo com o artigo $3^{\circ}$ do código em questão é função exclusiva do profissional de Educação Física:

(...) coordenar, planejar, programar, supervisionar, dinamizar, dirigir, organizar, avaliar e executar trabalhos, programas, planos e projetos, bem como prestar serviços de auditoria, consultoria e assessoria, realizar treinamentos especializados, participar de equipes multidisciplinares e interdisciplinares e elaborar informes técnicos, científicos e pedagógicos, todos nas áreas de atividades físicas e do desporto. (96.96/98, p.1)

Entretanto, a lei em tela não trás especificado a compreensão do que é atividade física, sendo assim, a definição do campo de atuação profissional da área é inócua. Essa falta de clareza na lei permite a ingerência do sistema CONFEF/ CREF, sobre o trabalho de qualquer manifestação corporal, a exemplo do yoga, da dança, da capoeira, das artes marciais, das lutas, dentre outras. Os trabalhadores dessas manifestações em alguns casos possuem até formação em nível superior. Todos esses profissionais são considerados leigos pelo sistema CONFEF/CREF. Assim sendo, o Conselho compreende que essas manifestações devem ser ministradas pelos profissionais de Educação Física, devidamente registrados no CREF de sua região. Além disso, o sistema CONFEF/CREF não considera que essas práticas surgiram antes mesmo do nascimento da própria Educação Física.

Os defensores da regulamentação da profissão se apoiaram no argumento de que a mesma 
serve como forma de resguardo aos trabalhadores da Educação Física, em tempos de neoliberalismo e relações de trabalho desregulamentadas. (NOZAKI, op.cit) Sendo assim, a saída encontrada pelos apologetas da regulamentação, para a crise do trabalho abstrato, que assola o campo da Educação Física brasileira é o ajuste ao sistema capitalista (Ibid).

Outro ponto que merece destaque na análise das relações entre conselhos profissionais e o trabalho do profissional que teve sua profissão regulamentada é a CLT, que regulamenta as leis trabalhistas no Brasil. Esse código estipula que os trabalhadores cujas profissões são regulamentadas podem ser funcionários contratados por empresas, como profissionais autônomos, liberais ou prestadores de serviço, sabemos que esses elementos são facetas das relações de trabalho altamente precarizada. Sob esse aspecto constatamos que as regulamentações das profissões são uma falácia, que na verdade significam a desregulamentação do trabalho, bem como a reserva de vagas em um mercado de trabalho precário.

Assim sendo, o "inimigo a ser atacado" se torna o trabalhador, principalmente, os considerados leigos e não mais os detentores dos meios de produção, no caso da Educação Física os empresário que transformaram a cultura corporal em mercadoria.

De acordo com o princípio dos conselhos profissionais, não é necessário que o trabalhador possua os conhecimentos necessários para intervenção em uma determinada área profissional, o mais importante é que esse trabalhador seja registrado. Desse modo, a legalidade apresenta-se superior à legitimidade. Evidências de tal afirmativa podem ser encontradas na própria fala do Presidente do CONFEF, Jorge Steinhilber, o qual, dentre outros, o que mais se empenhou na luta pela regulamentação da profissão. Disse ele que: as atividades recreativas, ou em clubes, academias de ginástica, resorts, hotéis condomínios, dentre outras, era "terra de ninguém, espaço vazio. Sendo espaço vazio qualquer um pode ocupá-lo. Portanto, devemos nós ocupá-lo antes que outros o façam" (STEINHILBER, 1996, p.51). O Conselheiro ainda afirma que a Educação Física pode ser uma profissão que ocupe todos os espaços, nas academias, nos clubes, nos condomínios e etc. Sendo necessário apenas o instrumento jurídico. Ou seja, basta regulamentar a profissão (ibid).

Entretanto, é importante salientar que na década de 1940 já havia a discussão referente à regulamentação da profissão da Educação Física. Contudo, a mesma não fora 
possível, pois o trabalhador da área atuava quase que exclusivamente no ambiente escolar e o mesmo é regulamentado (NOZAKI, op.cit).

Assim sendo, a regulamentação da profissão só foi possível mediante as mudanças ocorridas no trabalho do professor Educação Física, no que se refere ao campo de atuação profissional. Além disso, outra importante contribuição à regulamentação foi o processo de crise da educação e a particular desvalorização da Educação Física no espaço escolar, pois os trabalhadores da área, já não se sentiam mais, como o fora no passado professores. Sendo assim, eles próprios começaram a clamar pela regulamentação da profissão. Neste particular merece destaque a construção do consenso em torno da regulamentação. O referido consenso se deu a partir da constituição da subjetividade do trabalhador da área, pois o grupo pró-regulamentação aproveitou o momento de desvalorização do magistério para incutir nos trabaIhadores da Educação Física à idéia de profissional em detrimento da de professor. Entretanto, assim como Grawryszewski, (2008) defendemos a idéia de que essa profissão não existe, pois o elemento pedagógico está presente no trabalho do professor de Educação Física independente da sua área de atuação, sejam em clubes, escolas, academias, ou qual- quer outro espaço. O outrora professor de Educação Física, hoje, se reconhece como profissional liberal que vai vender os seus serviços no mercado do fitness. Entretanto, esse mercado, acompanhando a tendência do setor de serviços mostra-se desregulamentado e o que prevalece nas relações trabalhistas são as negociações entre as partes. De um lado, o capital; do outro, o trabalho. Contudo, como sabemos na atual fase de desenvolvimento capitalista marcada pela crise do desemprego e o elevado exército de reserva, na correlação de forças entre capital e trabalho, o primeiro grupo tem se destacado como vencedor.

Cabe ressaltar que a mudança na caracterização do trabaIhador da Educação Física, que de professor passa a ser profissional de Educação Física favoreceu os empresários do âmbito do fitness, pois até mesmo a representação de classe desses trabalhadores sofreu alterações substanciais. Nessa perspectiva, o professor da Educação Física, independente da área de atuação, dentro ou fora da escola, até então, era representado pelo sindicato dos professores e hoje, os trabalhadores que atuam fora da escola quando são representados por algum sindicato, esses possuem poder de representatividade e de negociação inferior ao apresentado pelo sindicato dos professores. 
Outro dado relevante é que os professores que trabalham em academias de ginástica, quando possuem carteira assinada, são registrados como instrutores de atividade física e não professores. Isso, porque caso esses trabalhadores fossem registrados como professores, os empresários teriam que respeitar o piso salarial e outras condições de trabalho negociadas com o sindicato dos professores. Esses por sua vez representam toda a categoria e não apenas os trabalhadores da Educação Física, portanto, possuem maior representatividade e poder de negociação superior quando comparado aos sindicatos dos instrutores de atividade física, ou profissionais de Educação Física.

A ACAD foi fundada em 20 de maio de 1999, a princípio a entidade abrangia apenas a cidade do Rio de Janeiro, sendo denominada de Associação das Academias do Estado do Rio de Janeiro, ACADRio. No ano de 2003 a associação tendo em vista, o "crescimento e fortalecimento da ACAD- Rio e da necessidade da existência de uma instituição nacional consolidada, que congregue e represente nacionalmente a indústria o Fitness" (ACAD, p. 11) transformou-se em ACAD- Brasil, uma entidade de abrangência nacional, que tem como um dos principais objetivos de acordo com o próprio estatuto da associação promover e proteger a Indústria do "Fitness" em todo o território nacional, aqui incluídas as academias de atividades físicodesportivas e seus fornecedores.

A associação é formada pelos proprietários de academias, principalmente da cidade do Rio de Janeiro/RJ, onde a sede está localizada. No entanto, a referida entidade possui abrangência nacional sendo organizada por um conselho consultivo, um conselho fiscal e uma diretoria. Todos esses órgãos são formados por empresários do âmbito do fitness. Quatro são as formas de associados da entidade: as academias associadas, composta pelos proprietários das academias de ginástica no Brasil, as academias correspondentes, formada pelos proprietários de academias fora do país, os colaboradores, que são o grupo dos fornecedores de produtos ou serviços utilizados pelas academias associadas e os honorários, pessoas físicas ou jurídicas que tenham prestado relevantes serviços, na área do fitness.

No entanto, apenas as academias associadas podem compor a diretoria da associação, ou seja, apenas os proprietários ou sócios das academias do Brasil podem compor a diretoria da ACAD. Além disso, somente esses podem votar nas assembléias gerais e requerer convocação extraordinária 
de assembléia geral. A diretoria da entidade é composta por nove membros sendo um presidente e um vice-presidente. $\mathrm{O}$ mandato tem duração de três anos podendo haver uma reeleição. A ACAD tem sua diretoria renovada parcialmente a cada ano, pois três membros que tenham cumprido o mandato de três anos deixam a diretoria e entram outros três membros eleitos pelas academias associadas. $\mathrm{O}$ conselho consultivo é formado pelos expresidentes da associação e deve ser consultado quando a diretoria entender que há necessidade. $\mathrm{O}$ conselho fiscal é formado por três membros eleitos junto à diretoria e tem como função fiscalizar o trabalho e as ações financeiras da associação.

Outro dado relevante é que a ACAD- Brasil possui uma revista de publicação bimestral, destinada aos proprietários das academias e distribuída gratuitamente para todas as academias associadas. Nessa revista há matérias relacionadas aos temas, marketing, questão jurídica, perspectivas do mercado, gestão empresarial, dentre outros.

No que se refere ao SINDACAD/RJ, o mesmo foi criado em 2005 e é sindicato dos proprietários das academias de ginástica da cidade do Rio de Janeiro. A ACAD nomeou uma comissão jurídica para estudos sindicais composta pelos advogados Álvaro Cravo, Ricardo Abreu e Pedro Aquino, cujo objetivo era a criação do sindicato patronal que pudesse representar os empresários das academias de ginástica. De acordo com notícia publicada na página da ACAD, na internet, a criação desse sindicato traria duas vantagens, dentre elas, a possibilidade de estabelecer uma convenção coletiva de trabalho, como podemos perceber na passagem que se segue.

A grande vantagem da criação de um sindicato específico da categoria é que a contribuição sindical obrigatória será destinada, na sua integralidade, a despesas do interesse das academias, o que não ocorre em relação aos sindicatos por similaridade, em que várias categorias estão representadas dentro de um mesmo órgão sindical. Outra vantagem da criação do SINDACAD/RJ é a possibilidade efetiva de existir uma convenção coletiva específica da categoria em nível nacional, através de parcerias com outros sindicatos patronais de academias. (ACAD, 2005)

Antes mesmo da consolidação do SINDACAD/RJ os seus idealizadores já pensavam em algumas questões que deveriam compor a convenção coletiva de trabalho da 
categoria. Eles propunham, para os anos de 2004 e 2005, o piso salarial de $\mathrm{R} \$ 289,42$ para os professores de Educação Física, denominados por eles de instrutores. Além disso, ainda propunham possibilidade de contratação por tempo parcial, remuneração de por hora/ aula de R\$ 2,31 para os trabalhadores graduados em Educação Física. No ano de 2010 foi aprovada uma nova convenção coletiva de trabalho o piso salarial definido é de $R \$ 600$ e a remuneração por hora/aula de $\mathrm{R} \$ 4,00$.

Contudo, apesar dos esforços empreendidos por parte da ACAD, apenas em 26 de abril de 2006 foi expedida pelo Ministério do Trabalho e Emprego, a Certidão de Registro Sindical do SINDACAD/ RJ (ACAD, n³1, 2006), por motivos desconhecidos por nós e no mesmo ano foi aprovada a convenção coletiva de trabalho que passou a vigorar a partir de maio. A mesma revista ainda ressalta que esse sindicato possui abrangência municipal e que de acordo com a proximidade da base, todos os sindicatos deveriam se organizar dessa forma. Isso nos remete a discussão das negociações coletivas de trabalho que foram propostas pela burguesia industrial durante toda a década de 1990, pois a preferência era por acordos no nível da própria empresa ou, municipal, principalmente quando as categorias se encontram mais desmobilizadas. Os próprios idealizadores do sindicato elaboraram o seu primeiro estatuto. A matéria publicada na revista da ACAD $n^{\circ}$ 21 (2004), antes da fundação do SINDACAD/RJ, dizia que as academias ganhariam mais força com a formalização do sindicato patronal, sobretudo, no âmbito jurídico e trabalhista.

Com a formalização do Sinda$\mathrm{cad} / \mathrm{RJ}$, prevista para o primeiro trimestre de 2005, as academias vão ganhar ainda mais força $\mathrm{e}$ representatividade, desta vez nos âmbitos jurídico e trabalhista. E mais: com a criação de um sindicato exclusivo da categoria no Rio, abre-se um precedente para que outros municípios e estados do país se organizem em prol do segmento, fazendo com que o céu seja o limite para seu crescimento. Não foi à toa que dedicamos à capa desta edição ao tema. Os detaIhes do lançamento deste novo e fundamental aliado estão aqui, na íntegra. (lbib, p. 14)

Portanto, o SINDACAD/RJ foi uma estratégia empresarial utilizada pela ACAD, cujo objetivo é a realização de convenções coletivas de trabalho, para favorecer a classe patronal, tendo em vista que apenas o sindicato patronal da categoria e 
o sindicato dos trabalhadores da mesma categoria podem realizar esse tipo de acordo. Conforme visto SINDACAD E ACAD mantém íntimas relações representando o mesmo grupo de empresários da cidade do Rio de Janeiro. Indo mais além, podemos dizer que ACAD e SINDACAD fazem parte de um único organismo, que atua cada um, nas questões específicas, que competem a sua área de representação. Portanto, ficou clara a relação entre ACAD e SINDACAD/RJ, entretanto, ainda cabe destacar a relação existente entre ACAD/SINDACAD/RJ e CONFEF/CREF.

\section{Aproximação institucional entre CONFEF/CREF, ACAD/ SINDACAD}

Em maio de 2003, o CREF-1 lançou uma campanha de Marketing que estimulava os médicos a prescreverem a prática de atividades físicas para os seus pacientes. A ACAD criou uma comissão de apoio para o projeto. Em junho do mesmo ano antes mesmo da posse da nova diretoria da associação, seu presidente eleito, Djam Madruga apresentou em assembléia da entidade, a parceria entre ACAD e o sistema CONFEF/CREF. Essa parceria previa que todas as academias tivessem seus profissionais registrados e que fossem também registradas, contudo, o registro para as academias era gratuito, devendo só os profissionais paga-lo. (MADRUGA, 2003).

A revista em questão, ainda apresenta uma foto da festa Black-tie, em comemoração ao $1^{\circ}$ de setembro, dia do profissional de Educação Física, que aparecem o presidente do CONFEF e vários diretores da ACAD. De acordo com a matéria publicada pela revista a festa foi promovida pelo CREF-1 e reuniu vários representantes das academias e instituições ligadas à atividade física. A referida festa mostrou quem realmente tem a comemorar com o dia do profissional da Educação Física, os proprietários das academias de ginástica. (ACAD, 2003 n 16,. p.35)

A revista da associação no 17 (2003) trás matéria referente ao $4^{\circ}$ encontro de fitness Brasil de abrangência internacional. Esse encontro é realizado por empresários do âmbito do fitness para que questões de pertinência ao setor possam ser discutidas. A ACAD participou na organização do evento. Além disso, seus diretores proferiram palestras. No interior desse encontro, também, houve um fórum de debates e representantes da ACAD e do sistema CONFEF/CREF formaram uma mesa que versava acerca da formação profissional da área e 
da regulamentação do estagiário. $\mathrm{O}$ presidente do CONFEF afirmou que prezava pela formação profissional de qualidade e que o mercado das atividades físicas estava em grande expansão assim completa ele, a formação está diretamente ligada ao desenvolvimento da indústria do fitness. (lbid).

Em entrevista concedida à revista da associação seu então presidente Djam Madruga (2004), destaca a busca de parcerias por parte da ACAD, em especial a parceria com o sistema CONFE/CREF. O Presidente da associação enfatiza que uma das melhores parcerias da ACAD se dá com o sistema CONFEF/CREF.

Uma das nossas melhores parcerias se dá com o sistema CONFEF/CREFs, que é de vital importância para a ACAD, pois juntos vamos conseguir desenvolver o setor do fitness e aumentar o número de empregos gerados. Estamos muito mais contentes com o andamento dessa parceria, a atuação do CONFEF, em especial do Presidente Jorge Steinhilber está bastante afinada com a ACAD. Um dos fatores importantes na Educação Física no Brasil foi a regulamentação da Profissão de Educação Física e grande parte desse crédito precisa ser dado ao Prof. Steinhilber. Entende- mos que essa parceria vai ajudar muito tanto as academias como os Profissionais de Educação Física, até porque as academias hoje são as maiores empregadoras de Profissionais de Educação Física no Brasil. Logo, é vital que o CONFEF e a ACAD trabalhem juntos para proteger esse setor e seus profissionais. (MADRUGA, 2004, p.15)

Além disso, na compreensão de Madruga a regulamentação da profissão foi um passo muito importante para a Educação Física brasileira, sendo assim, a ACAD vem fazendo campanhas para que os trabalhadores das academias sejam registrados e para que só sejam contratados profissionais que possuam registro no conselho.

O Presidente da ACAD, ainda destaca a aproximação dessa associação com o

\section{CREF-1:}

Também gostaria de destacar nossa aproximação com o CREF-1, do Rio de Janeiro, na pessoa de seu Presidente, Ernani Contursi, com o qual dispomos de uma verdadeira parceria operacional. Mantemos um encontro mensal de trabalho, num exercício que pode ser aplicado em todo o Sistema. Indicamos um dos conselheiros na atual gestão, o nosso ex-presidente 
Pedro Aquino, que é Profissional de Educação Física e advogado com grande experiência em gestão de academias no Brasil. (Ibid, p.16)

Esse conselheiro do CREF-1 indicado pela ACAD, continua na diretoria desse CREF é também vice diretor da ACAD e um dos três advogados que fundaram o SINDACAD/RJ. Essas informações foram publicadas, também, na revista $\mathrm{n}^{\circ}$ 11 do CONFEF, em 2004.

No primeiro congresso da ACAD ocorrido em março de 2004, o presidente do CREF-1, na ocasião, esteve presente, parabenizou a associação e disse que o evento era muito importante para as academias só tendo a somar para o setor (CONTURSI, 2004) Além disso, CONFEF/ CREF, ACAD e outras associações patronais, FREBACAD e UNEN, têm defendido desde 2003, o enquadramento das academias de ginástica na área da saúde. Isso traria grandes benefícios aos proprietários das academias no que se refere à carga tributária, pois os impostos pagos por elas diminuiriam consideravelmente. (ACAD, $\mathrm{n}^{0} 18,2004$; CONFEF, $\left.n^{\circ} 16,2005\right)$. Mediante ao exposto percebemos que o sistema CONFEF/CREF mantém relações com outra entidade patronal. Além disso, o presidente dessa federação, em 2005, também era conselheiro federal, no mesmo ano.
Outra mostra da parceria entre ACAD e CONFEF/CREF foi o empenho que ambas as entidades tiveram na criação de uma Frente Parlamentar em Defesa da Atividade Física (FPDAF). Essa frente foi criada em 23 de julho do ano de 2003. O objetivo da ACAD e do CONFEF/ CREF com a criação da (FPDAF) é garantir isenção fiscal às academias. Para tanto, utilizam o argumento de que elas servem como centros de saúde preventiva, sendo assim, desoneram o Estado com gastos relacionados ao tratamento de doenças que poderiam ser evitadas com a prática de atividade física.

O Presidente da frente empresário e Deputado eleito pelo Partido da Frente Liberal (PFL), hoje, Democratas (DEMO) Cláudio Cajado, afirma que a criação da frente é primordial para o incremento do setor do fitness. Em entrevista à ACAD, acerca da criação da FPDAF o presidente do CONFEF, Jorge Steinhilber declara que o CONFEF, a ACAD e a FPDAF devem agir em ação conjunta na "busca de incentivos fiscais e, principalmente, a ampliação de incentivo à prática de atividades físicas que resultará no desenvolvimento da indústria do fitnees" (STEINHILBER, 2003.p.25) Steinhilber, afirma ainda que:

A sociedade será a grande beneficiária da implantação das 
atividades física, resultando na ampliação geral para o mercado do fitnees. À medida que cresça a prática, aumenta a procura pelos locais; conseqüentemente, há necessidade de ampliação de oferta, resultando em busca de roupas adequadas e calçados, além de outros agregados, aquisição de maquinários, razão do surgimento de academias, e clínicas para atender a demanda. Um verdadeiro círculo vicioso crescente. (Ibid.: p.25).

Cláudio Cajado, também em entrevista a ACAD por ocasião da criação da FPDAF, considera que "as academias de ginástica promovem saúde", assim sendo, na compreensão dele, o setor privado contribui com o setor público, diminuindo os gastos do Governo Federal com a saúde, podendo-se pensar na criação de um projeto no qual as academias tenham seus impostos reduzidos. (CAJADO, 2003). O Deputado ainda compreende que o crescimento do acesso da população à prática de atividade física deve ser garantido através de “parceria público privado, como por exemplo, a ocupação dos horários vagos nas academias para que a população de baixa renda possa usufruir dos benefícios das mesmas, em troca de incentivos fiscais" (Ibid.; p.26).
Ricardo Abreu ao assumir a presidência da ACAD em setembro de 2005, no seu primeiro discurso relatou que a sua gestão seria marcada por parcerias para que a entidade pudesse ter maior representatividade em âmbito nacional, dentre elas está a parceria com o sistema CONFEF/CREF, que de acordo com o presidente da associação é uma instituição reconhecidamente forte na indústria do fitness (ABREU, 2005)

Em sua edição de $n^{\circ} 32$ (2006) a revista da associação publicou uma matéria relacionada à parceria estabelecida entre ACADMINAS e ACAD-Brasil para que todos os benefícios das academias associadas à ACAD-Brasil fossem desfrutados, também, pelas associadas à ACADMINAS. Nessa mesma matéria foi exposta a cerimônia de consolidação da entidade em questão e dentre as personalidades presentes estava o CREF da respectiva região. (lbid)

No IV Congresso da ACAD de acordo com matéria publicada na revista da associação, dentre os temas de discussão estava presente o que se relaciona a importância do profissional de Educação Física ser registrado no CREF de sua região. Além disso, estavam previstas palestras sobre "Regularização trabalhista, Contrato de prestação de serviços, Contrato de tempo-parcial, 
Terceirização de serviços e Regularização do autônomo (Personal Trainer"). (ACAD, 2007, n 35, p. 20). Para ministrar as referidas palestras foram convidados, de acordo com a matéria, grandes especialistas, dentre eles, Manuel Tubino, conselheiro do CONFEF e Pedro Aquino, conselheiro do CREF-1. (Ibid) CONFEF, CREF-1 e ACAD ainda organizam feiras de fitness que ocorrem no Rio de Janeiro, tendo em 2007, ocorrido paralelamente o $\mathrm{V}$ Congresso $\mathrm{da}$ ACAD. Além disso, esses três, em 2002 organizaram o primeiro encontro dos proprietários das academias no Brasil.

Todavia, apesar das evidências comprovarem a relação entre ACAD/SINDACAD e sistema CONFEF/CREF, principalmente CREF-1, esse último em seu jornal de $\left(n^{\circ} 20\right)$ publicou matéria relacionada ao "Trabalho Escravo nas Academias de Ginástica". De acordo com o atual presidente da associação, Carlos Eduardo Consenza Rodrigues (2008), o CREF-1 tem escutado várias queixas, dos trabalhadores da Educação Física, referente às condições de trabalho nas academias de ginástica, sendo eles, os grandes mentores da manifestação.

Os profissionais são os grandes mentores desta batalha. Durante todo este tempo de existência do CREF1, nós escutamos estas queixas e, na verdade, sabíamos que o que eles precisavam era de ajuda. Agora, chegou a hora. Vamos para as ruas gritar por dignidade para nossa profissão (Ibid, p.2)

Quando questionado por que o conselho resolveu se manifestar em relação ao fato, o seu presidente disse que foi porque os professores procuram insistentemente o CREF-1 para queixar-se das condições de trabalho.

Devido ao grande número de profissionais que procuram diariamente o Conselho para se queixar dos abusos praticados no mercado, em relação às condições trabalhistas impostas pelos empregadores das academias. Muitos destes já abandonaram a profissão ou consideram a Educação Física como subemprego, ou seja, não depende dela para sustentar a sua família. (Ibid, p.2)

Desse modo, o sistema CONFEF/CREF começa a ter sua hegemonia ameaçada, tendo em vista que todos os conselhos profissionais são mantidos pelos trabalhadores da profissão que foi regulamentada. Sob esse prisma o abandono da profissão pelos trabalhadores da Educação Física, bem como as insatisfações e reclamações recorrentes 
abala a supremacia do conselho. Os trabalhadores que abandonaram a profissão tendem a procurar os CREF em que são registrados para pedir o cancelamento do registro.

Desse modo, as manifestações em questão vêm sendo utilizadas pelo conselho na tentativa de manter a hegemonia no campo da cultura corporal. Para tanto, o sistema CONFEF/CREF se utiliza, antes mesmo de sua consolidação, da dupla "coerção e consenso" (GRAMSCI, op.cit.) A própria lei 96.96/98 já é uma forma de coerção dos trabalhadores das manifestações corporais, pois para o exercício da profissão, nos campos não escolares, é obrigatório o registro no conselho profissional. Todavia, conforme visto para que a profissão pudesse ser regulamentada foi necessária a criação do consenso e os próprios trabalhadores da Educação Física passaram a reivindicar a regulamentação. Isso posto, o Conselho se mantém hegemônico, a priori, coagindo os trabalhadores das manifestações corporais a se registrarem, sob o risco de perder o emprego ou, pior ainda, de responder processo judicial pelo exercício ilegal da profissão. Essa prática é bastante comum ao sistema CONFEF/CREF.

O jornal da MOVAPEF, órgão ligado ao sistema CONFEF/CREF relatou que as grandes academias da cidade do Rio de
Janeiro já aceitaram o piso salarial sugerido pelo CREF-1 que é de $\mathrm{R} \$ 10,67$ hora/aula. Contudo, o problema ainda reside nas pequenas academias. Conforme visto anteriormente os conselheiros do CREF-1, que são empresários do âmbito do fitness são proprietários de grandes academias, então o aumento do piso salarial poderia até favorecê-los, pois há a possibilidade das pequenas academias falirem e assim o CREF-1 poderia coordenar uma espécie de monopólio das academias de ginástica, na cidade do Rio de Janeiro.

Apesar dos diretores da ACAD/SINDACAD, também serem proprietários de grandes academias a base que mantém essa organização em funcionamento é composta por academias de pequeno, médio e grande porte. Portanto, para manterse organização hegemônica, no âmbito do fitness, deve representar os interesses de todas as academias. Por outro lado, apesar do sistema CONFEF/CREF representar a burguesia do setor do fitness, quem mantém esse conselho em funcionamento são os trabalhadores da Educação Física, então é justificável o aparente antagonismo entre ACAD/ SINDACAD e CONFEF/CREF. É favorável ao conselho, nesse momento, para defender seu interesse histórico se manifestar contra o piso rebaixado que os professores 
de Educação Física são submetidos nas academias de ginástica.

Esse episódio de aparente embate entre ACAD/SINDACAD e CONFEF/CREF expressa uma luta entre as frações da classe burguesa que operam no campo da cultura corporal com objetivo de lograrse hegemônica. Como era de se esperar o sistema CONFEF/CREF, em suas manifestações, não destina criticas a apropriação do trabalho pelo capital, ao contrário, em uma de suas faixas propaga a idéia da conciliação de classe, com a seguinte frase: "Patrão que é patrão é contra a escravidão" (Jornal do CREF-1 no 20, op.cit, p.6)

\section{Conclusão}

Através da análise aqui realizada é possível concluir que na atual fase de acumulação capitalista, representada em grande parte pelo crescimento do setor de serviços, para a burguesia não é mais central se apropriar da cultura corporal na forma da Educação Física. No entanto, torna-se central essa apropriação na forma de mercadorias a ser vendida primordialmente nas academias de ginástica. Nesse cenário, nasce a burguesia do âmbito do fitness, que a partir dos anos de 1990 começa a se organizar enquanto classe, sobretudo, em três organismos fundamentais: o sistema CONFEF/CREF a ACAD e o SINDACAD. Ainda é possível afirmar que essas instituições mantêm íntimas relações atuando intensamente na precarização do trabalho do professor de Educação Física.

\section{Referências}

ABREU, Ricardo. Contrato por tempo parcial: aplicação e vantagens. ACAD, Rio de Janeiro, n. 20, p. 6, mar/abr. 2004.

ACAD. Convenção Coletiva de Trabalho. ACAD, Rio de Janeiro. S/d.

ACAD. Estatuto da ACAD. ACAD, Rio de Janeiro. 2003. Disponível em http://www.acadbrasil.com. br/institucional/estatuto.htm.

ACAD. A Convenção Coletiva do Sindicato das Academias do Rio de Janeiro. ACAD. Rio de Janeiro, 2004. Disponível em:http://www. acadbrasil.com.br/artigos/artigos assunt_jur_02.htm.

ACAD. Eles usam black-tie. ACAD. Rio de Janeiro, n 16, p.36, set. 2003.

ACAD. Marcha pelo simples contamos com você nesta empreitada. ACAD. Rio de Janeiro, n 18, p. 22, mar. 2004.

ACAD Sucesso! Presenças ilustres e aprovação do público fazem do $1^{\circ} \mathrm{ACAD}$ congresso e exposição 
um divisor de águas na discussão sobre a capacitação no setor do fitness. ACAD. Rio de Janeiro, n 20, p. 8, jun. 2004.

ACAD. SINDACAD: representatividade e fortalecimento para o setor. ACAD. Rio de Janeiro, n 20, p. 14-15, jun. 2004.

ACAD. ACAD Brasil e ACADMINAS: união pelo crescimento do setor. ACAD, Rio de Janeiro, n 32, p. 17, jul/ago. 2006.

ACAD. Congresso ACAD Brasil inaugura o centro de convenções Rio cidade nova. ACAD, Rio de Janeiro, n 35,p. 22, jan/fev. 2007.

BERGALLO, Carlos Heitor. A Indústria em Números. ACAD, Rio de Janeiro, n 18, p.16, mar. 2004.

B ERTEVELO， G il berto. Reconhecimento das academias na área da saúde. REVISTA EF, Rio de Janeiro, ano 5, n 16, p.2324 jun 2005.

BRASIL. Lei no 9.696, de $1^{\circ}$ de setembro de 1998. Dispõe sobre a regulamentação da Profissão de Educação Física e cria os respectivos Conselho Federal e Conselhos Regionais de Educação Física. Diário Oficial da União, Brasília, DF, 2 set.1998

BRUM, Edson, Em Primeiro Lugar. In:

Revista da ACAD, Rio de Janeiro $n^{\circ} 25$, p.14, mai/jun, 2005.

CAJADO, Cláudio e STEINHILBER, Jorge. Incondicional:
Parlamentares se unem em torno do fomento à pratica de atividades físicas. In: Revista da ACAD, Rio de Janeiro: n16, p.24- 26 set, 2003.

Carta do Setor de Atividades Físicas aos Lesgisladores, In: www. fdatividadefisica.com.br.

CREF-1. Movimento contra o trabalho escravo nas academias. Movimento contra o trabalho escravo nas academias: lideranças se unem na luta por melhores condições de trabalho para os profissionais. CREF-1 n 20, p. 6-7, $2^{\circ}$ sem. 2008 Disponível em: http://www.cref1.org.br/ img/jornal_cref/Jornal\%2020. pdf. Acesso em 25 de outubro de 2008.

CREF-1. Operação supino. Movimento contra o trabalho escravo nas academias: lideranças se unem na luta por melhores condições de trabalho para os profissionais CREF-1 n 20, p. 3, $2^{\circ}$ sem. 2008 Disponível em: http:// www.cref1.org.br/img/jornal cref/Jornal\%2020.pdf. Acesso em 25 de outubro de 2008.

CONTURSI, Ernani Bevilaqua. Grandes nomes valorizam a abertura dos trabalhos. ACAD. Rio de Janeiro, n20, p.20-21, jun. 2005.

FITNESS BRASIL Gestores da ACAD participam ativamente do evento. ACAD. Rio de Janeiro, n 17, p.16-17, dez. 2003. 
FRIGOTTO Gaudêncio. Educação e crise do capitalismo real. São Paulo: Cortez, 1996.

GRAMSCI, Antônio. Maquiavel, a política e o Estado moderno. 5 ed. Rio de Janeiro: Civilização Brasileira, 1991.

GAWRYSZEWSKI, Bruno. CONFEF: organizador da mercantilização do campo da Educação Física. Dissertação (Mestrado em educação). Faculdade de educação. Universidade Federal do Rio de Janeiro, Rio de Janeiro, 2008.

GIGANTE, Fitness Business, São Paulo, no 21, p. 34-36, set. 2005. MADRUGA, Djan. Nova diretoria é empossada em assembléia. ACAD. Rio de Janeiro, n 16, p.12-13, set. 2003.

MADRUGA, Djan. (entrevista) CONFEF e ACAD unindo forças em favor da Educação
Física. ACAD. Rio de Janeiro, n 20, p.14-17, mar. 2004.

MADRUGA, Djan. (entrevista) CONFEF e ACAD unindo forças em favor da Educação

Física. REVISTA EF. Rio de Janeiro, n 20, p.14-17, mar. 2004.

MADRUGA, Djan. Um ano de realizações. ACAD. Rio de Janeiro, n.21, p. 4, setout/2004.

MOVAPEF. Movimento pela valorização do professor de educação física: prestação de contas, 2008.

NOZAKI, Hajime. Educação Física e Reordenamento no Mundo do Trabalho: Mediações da regulamentação da profissão. Tese (Doutorado em Educação) - Faculdade de Educação, Universidade Federal Fluminense, Niterói, 2004.

\section{ABSTRACT}

The present article is inserted in an effort to understand the enterprise organization of the scope of fitness from the years of 1990. Specifically it searchs to establish the relations between these organizations. For in such a way, it carries through a referring historical passage to the creation of the three institutions treated here, searching to aclarar its interests of classroom. Still, it searchs through the magazines of the organizations to establish the relation between them. Finally, one concludes that the three organizations keep soul in accordance with relations acting its interests of classroom what precariza intensely the work of the professor of physical education. For ends of this work we detach as the representative organisms of the bourgeoisie of the scope of fitness system CONFEF/CREF, the ACAD (Association of the Academies of Brazil) and the SINDACAD (Union of the proprietors of the gymnastics academies).

Keywords: Work. Physical Education. Bourgeoisie of the scope of fitness. 